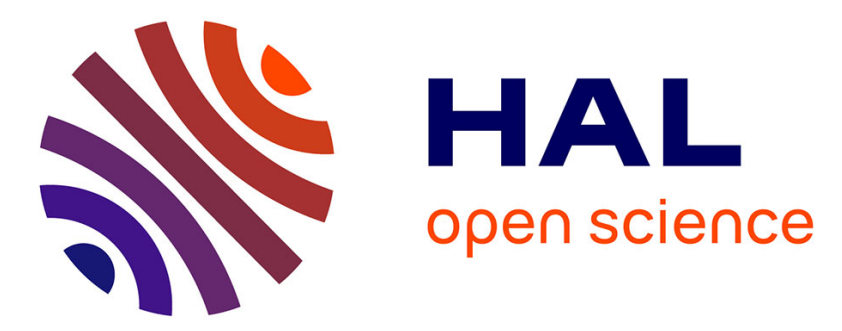

\title{
EXPERIMENTAL STUDY OF ACOUSTIC RESONANCES ON ELASTIC SPHERES AND HEMISPHERICALLY ENDCAPPED CYLINDERS
}

W. Madigosky, X. Bao, H. Uberall

\section{- To cite this version:}

W. Madigosky, X. Bao, H. Uberall. EXPERIMENTAL STUDY OF ACOUSTIC RESONANCES ON ELASTIC SPHERES AND HEMISPHERICALLY ENDCAPPED CYLINDERS. Journal de Physique Colloques, 1990, 51 (C2), pp.C2-427-C2-430. 10.1051/jphyscol:19902101 . jpa-00230381

\section{HAL Id: jpa-00230381 https://hal.science/jpa-00230381}

Submitted on 1 Jan 1990

HAL is a multi-disciplinary open access archive for the deposit and dissemination of scientific research documents, whether they are published or not. The documents may come from teaching and research institutions in France or abroad, or from public or private research centers.
L'archive ouverte pluridisciplinaire HAL, est destinée au dépôt et à la diffusion de documents scientifiques de niveau recherche, publiés ou non, émanant des établissements d'enseignement et de recherche français ou étrangers, des laboratoires publics ou privés. 
COLLOQUE DE PHYSIQUE

Colloque C2, supplément au $\mathrm{n}^{\circ} 2$, Tome 51, Février 1990

ler Congrès Français d'Acoustique 1990

\title{
EXPERIMENTAL STUDY OF ACOUSTIC RESONANCES ON ELASTIC SPHERES AND HEMISPHERICALLY ENDCAPPED CYLINDERS
}

\author{
W. MADIGOSKY, X.L. BAO* and H. UBERALL* \\ NSWC White Oak Laboratory, Code R31, Silver Spring, MD 20903-5000, \\ U.S.A. \\ * Department of Physics, Catholic University of America, Washington, DC \\ 20064, U.S.A.
}

Résumé - Nous avons obtenu les spectres expérimentaux des resonances acoustiques sur des sphères d'acier, et des cylindres d'acier terminés par des hemisphères. Les spectres étaient obtenus par rétrodiffusion acoustique, avec l'incidence ou axiale ou oblique dans le cas des cylindres. Nous avons interpreté théoriquement les spectres par la propagation des ondes de surface, en donnant un accord de phase sur un chemin de passage fermé.

Abstract - Acoustic resonance spectra were obtained experimentally for steel spheres and cylinders with hemispherical endcaps by acoustic backscattering (for cylinders: with both axial and oblique incidence). They were interpreted theoretically by surface wave propagation with phase matching over a closed path.

\section{1 - INTRODUCTION}

The character of an elastic object immersed in water can be extracted form its acoustic scattering signal analyticaliy $/ 1 /$ and experimentally $/ 2-4 /$. In the present study, the echo amplitudes and acoustic resonance spectra for steel spheres and cylinders with hemispherical endcaps were obtained by numerical (gated Fourier) processing of experimental data from backscattered waves. Sinusoidally modulated short pulses were incident in the axial direction and in discrete oblique directions for the finite cylinders. Resonance frequencies were extracted from the return echoes, and were interpreted by the phase-matching of surface waves propagating along closed paths.

\section{2 - RESONANCES ESTIMATED BY PHASE-MATCHING METHOD}

(a). In case of axial incidence, a resonance condition based on the phase-matching principle as formulated by Uberall et al $/ 5 /$ is used to estimate the resonances of elastic prolate spheroids and cylinders with hemispherical endcaps:

$$
\int \mathrm{k}_{\ell} \mathrm{ds}=2(\mathrm{n}+1 / 2) \pi, \quad \mathrm{n}=1,2, \ldots
$$

where $\mathrm{n}$ is an integer, and the term $1 / 2$ is caused by phase jumps when the surface waves pass the two focal points. The quantity $\mathrm{k}_{\ell}$ is the propagation constant of the $\ell$-th surface wave mode and it varies along the path as the surface curvature varies. For the cylinder with hemispherical endcaps, the resonance condition simplifies to:

$$
k_{\ell}(\dot{c})(L-2 \dot{a})+k_{\ell}(\dot{s}) \pi a=(n+1 / 2) \pi,
$$

where $k_{\ell}(c), k_{\ell}(s)$ are the propagation constants of the surface wave on the cylinder and on the sphere, respectively. L,a are length and radius of the cylinder, respectively.

(b) In general, for a smooth convex object resonant under the incidence of an acoustic wave, the resonance conditions based on phase matching of surface waves can be summed up as:

(i) The circumnaviagation paths of the surface wave are closed.

(ii) The phase matching condition is satisfied on the closed surface paths. 


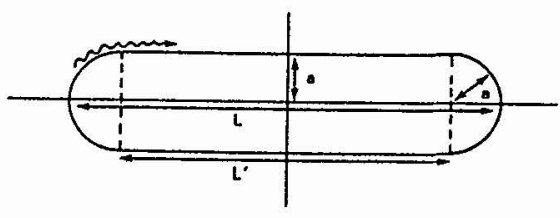

Fig. 1 - Surface wave propagation along the meridian of a cylinder with hemispherical endcaps.

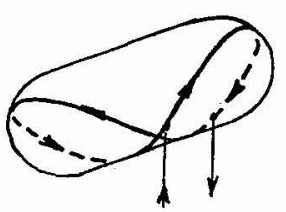

Fig. 2 - Surface wave propagation along a helical closed path.

(iii) There are a set of surface wave paths with a similar closed shape, therefore the phase matching can be satisfied simultaneously.

In case of non-axial incidence, conditions (1) and (iii) are usually not satisfied except at some special incident angles. One example is shown in Fig. 2. According to condition ( $i$ ), the helical angles $\alpha$ of surface paths or the incident angles $\beta$ of the sound wave can be obtained as

$$
\begin{aligned}
& \alpha_{m}=\operatorname{arctg} \frac{m \pi}{\nu a-2}, \\
& \sin \beta=(n+1 / 2) /\left[(k a)_{n, 1} \tan \alpha_{m}\right]=\left(C_{0} / C_{p}\right) \cot \alpha_{m}
\end{aligned}
$$$$
\mathrm{m}=1,2, \ldots
$$

where $(k a)_{n, \ell}$ or $C_{0} / C_{\ell}$ can be obtained by solving the wave equation of an infinite cylinder in case of obliquely incidence $/ 6 /$.

According to the second condition (ii), the resonance frequencies can be solved for by phase matching of the surface wave along the closed path,

$$
k_{1}^{(c)} a\left[(L-2 a) / a \cos \alpha_{m}\right]+k_{1}^{(s)} \pi a=\pi(n+1 / 2)
$$

The quantities $k_{\ell}(\varepsilon)$ and $k_{\ell}(\$)$ are wave numbers of the surface wave on the cylinder or the sphere; $k_{\ell}(\dot{c})$ changes with helical angles of the surface paths. The dispersion relations of $\mathrm{k}_{\ell}(\dot{s})(\mathrm{ka}) \boldsymbol{l}$ and $\mathrm{k}_{\ell}(\mathrm{c})(\mathrm{ka}, \alpha)$ can be obtained by solving the wave equations on a sphere and on añ infinite cylinder $/ 6,7 /$.

3 - RESULTS AND DISCUSSION

(a) Fig. 3 shows the observed pulse sequence in the echo from an $18 \mathrm{~mm}$-diameter steel sphere. The first echo pulse is the specular-reflected wave. Beginning from the second echo pulse, there appears a pulse sequence related to the $\ell=1$ mode, namely the Rayleigh surface wave. The $\ell=2$ mode and internal reflection pulses can not be seen

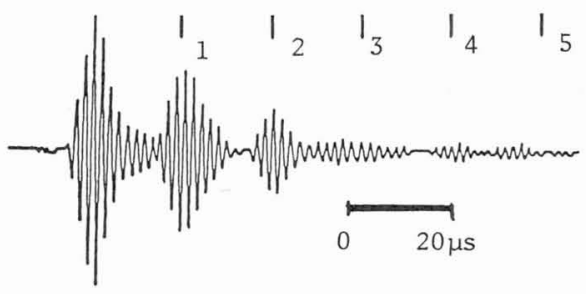

Fig. 3 - Backscattered pulse series from an $18 \mathrm{~mm}$-diameter steel sphere in water. 


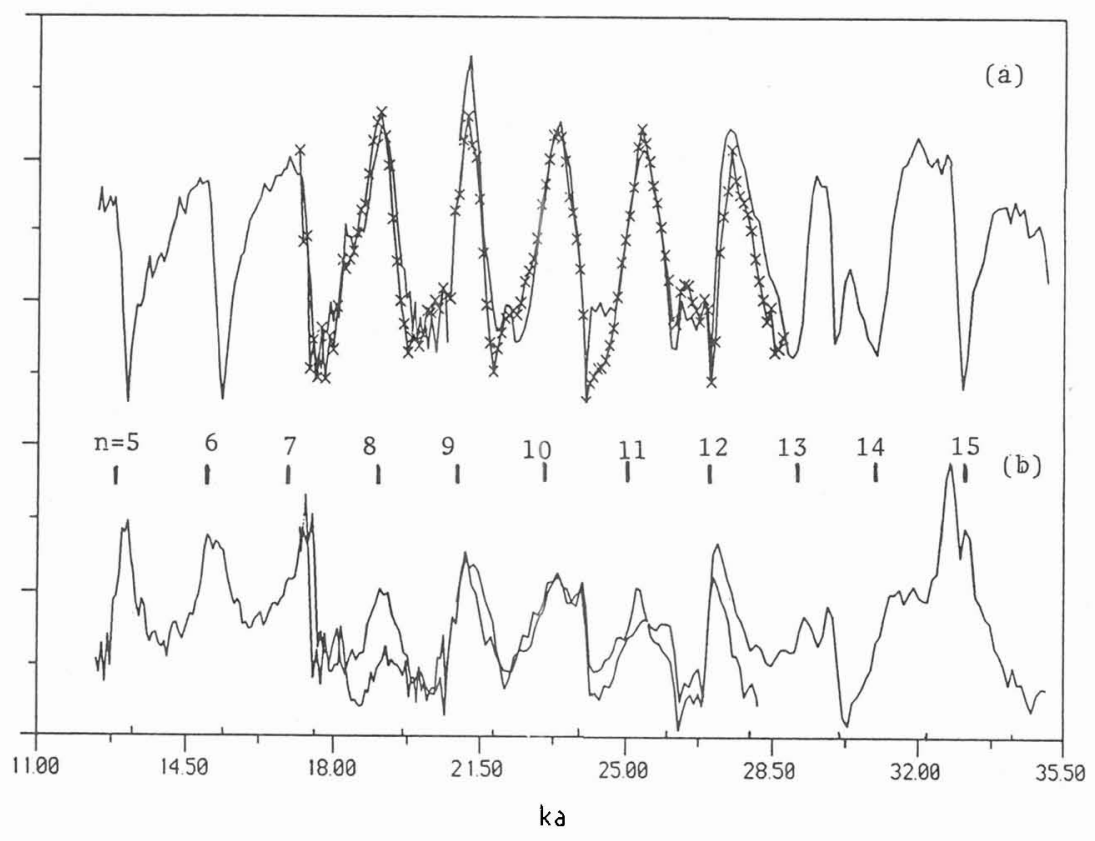

Fig. 4 - Normalized amplitude spectrum (a) and resonance spectrum (b) of stee1 spheres (diameters $D=13,18$ and $22 \mathrm{~mm}$ ) from data processing of echo wave form.

clearly. The resonance spectrum is obtained by removing the first echo pulse from the echo waveform and by data processing. In Fig. 4, the normalized amplitude spectrum (the "form function") and the resonance spectrum are shown over a broad region by employing steel spheres with different diameters. The results show that the resonance peaks basically coincide with the eigenfrequencies which are predicted theoretically (as indicated on the center scale) for the $\ell=1$ mode.

(b) Results for the steel cylinder with hemisperical endcaps are as follows. For the case of axial incidence the echo pulse sequence is shown in Fig. 5 . As seen from the indicated theoretical predictions, there appear echo pulses related to the Rayleigh wave starting from the third echo pulse. The second echo pulse, caused mainly by geometrical internal reflection and by the surface wave of the $\ell=2$ mode, is quite strong. In data processing for obtaining the resonance spectrum, the first one and the first two echo pulses were removed, respectively. As shown in Fig. 6, clear resonance peaks appear only when the first two pulses are removed in data processing. The results indicate that for the case of axial incidence, the resonances of a capped cylinder can be successfully extracted experimentally using short pulses.

(c) For the case of non-axial incidence, the possible resonance modes based on the phase matching of surface waves at some special incident angles were predicted and are compared with the experimental results. The agreement is not as good as in the case of axial incidence. As mentioned above, for oblique incidence the resonance conditions related to phase matching of surface waves are not perfectly satisfied. Perhaps this is one of the reasons for the mentioned partial disagreement.

\section{REFERENCES}

/1/ Flax, L., Dragonette, L. R., and Ubera11, H., "Theory of elastic resonance excitation by sound scattering," J. Acoust. Soc. Am. 63 (1978) 723.

12/ Maze, G., and Ripoche, J., "Methode d'isolement et d'identification des resonances de cylindres et de tubes soumis à une onde acoustique plane dans I'eau," Rev. Phys. Appl. 18 (1983) 319 . 


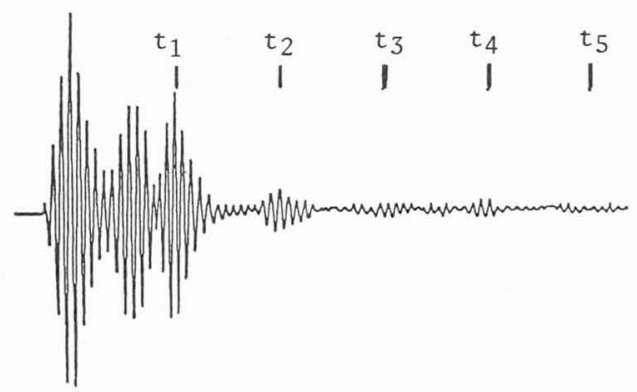

Fig. 5 - Backscattered pulse sequence from a steel cylinder with hemispherical endcaps (axial incidencé).

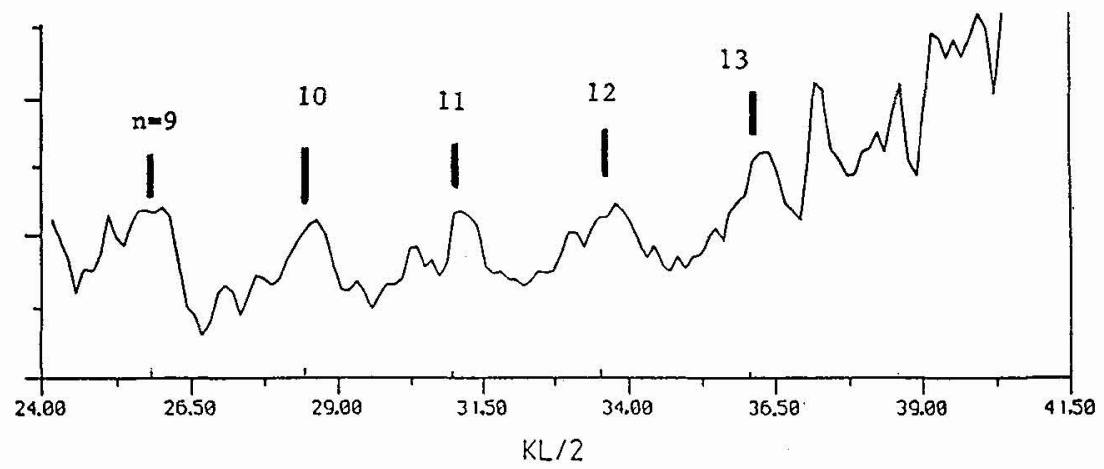

Fig. 6 - Resonance response of steel cylinder with hemispherical endcaps (axial incidence), from Fourier analysis of Fig. 5 .

13/ Numrich, S. K., Dale, N., and Dragonette, L. R., "Generation and exploitation of plate waves in submerged, air-filled shells," in Advances in Fluid-Structure Interactions (ASME, New York, 1984), PVP vol. 78/AMD vol. 64, pp. 59-74.

14/ de Billy, M., "Determination of the resonance spectrum of elastic bodies via the use of short pulses and Fourier transform theory," J. Acoust. Soc. Am. 79 (1986) 219.

15/ Uberall, H., et al., "Resonance spectra of elongated elastic objects," J. Acoust. Soc. Am. $\frac{81}{x}(1987) 312$.

16/ Bao, X. L., Cao, H., and Uberal1, H., "Resonances and surface waves in the scattering of an obliquely incident acoustic field by an infinite elastic cylinder," J. Acoust. Soc. Am., to be published.

17/ Vogt, R. H., and Neubauer, W. G., "Relationship between acoustic reflection and vibrational modes of elastic spheres," J. Acoust. Soc. Am. 60 (1976) 15. 